\title{
Experimental Investigation of the Small-scale Fixed Multi-chamber OWC Device
}

\author{
Mohammad Shalby ${ }^{* *}$, Ahmed Elhanafi ${ }^{2}$, Paul Walker ${ }^{3}$, David G. Dorrell ${ }^{4}$, Ahmad Salah ${ }^{5}$ and \\ Mohamed R. Gomaa ${ }^{1,6}$
}

\begin{abstract}
Sea wave energy generators or converters (WECs) have the potential to become a viable technology for clean, renewable energy production. Among the WEC technologies, the oscillating water columns (OWCs) are the most common WEC devices studied. These have been studied and developed over many years. Multi-chamber oscillating water columns (MC-OWC) have the potential to have a higher energy conversion when extracting energy in mixed sea states than single-chamber devices. In the work reported in this paper, physical experiments are carried under regular wave conditions to test the wave power extraction of a fixed MC-OWC small-scale model. The Power Take-Off (PTO) of the device is simulated using orifice plates. The flow characteristics through these orifices are pre-calibrated such that the extracted power can be obtained only using the pressure measurement. Wave condition effects on the damping of the PTO of the device power extraction are addressed. The test results illustrate that the PTO system damping is critical and affects device performance.
\end{abstract}

Keywords: Ocean wave energy, Energy conversion, Oscillating water column, Multi-chamber OWC

\section{Introduction}

Renewable energy sources have a fundamental role in the reduction of air pollution, especially $\mathrm{CO}_{2}$ emissions. Solar, wind, and ocean energies are being harnessed as future sources of zero-emissions energy [1]. Among all the renewable energy sources, ocean resources have the potential to become a major contributor to the clean energy market with areas of substantial energy density around the world [2-4]. Despite the abundance of ocean energy, it remains the least developed renewable energy sector, particularly when compared to wind or solar. This is due to technical challenges being the development of technologies to generate optimum energy, at the lowest cost, with the least environmental impact. Also, the policy and regulation challenges and investment challenges [5,

\footnotetext{
*Correspondence: Mohammad.shalby@ahu.edu.jo

${ }^{1}$ Mechanical Engineering Department, Faculty of Engineering, Al-Hussein Bin Talal University, Ma'an 71111, Jordan

Full list of author information is available at the end of the article
}

6]. Recently, there has been a growing interest in the use of the energy in sea waves for electricity generation [7-9]. A large variety of Wave Energy Converters (WECs) have been proposed and tested under different conditions [10]. This has led to several successfully demonstrated prototype devices that have been connected to commercial power grids [11, 12]. Most devices remain at the initial stage of development. Oscillating water columns (OWC), either fixed structure or floating, are one of the most effective ways of generating electrical energy from the kinetic energy contained in ocean waves [12-14]. There are few studies on multi-chamber OWC (MC-OWC) device in terms of its concept and performance $[15,16]$. However, the OWC is probably the most sea-deployed type of WEC. Mutriku is one of the early wave farms which has fourteen OWCs [17]. According to Falcão et al. [18] and Nachtane et al. [19], most OWC research has been centred on stand-alone devices, i.e., with only one chamber, and there are either shorelines or near-shore. The optimum performance of these devices is usually obtained at the chamber resonant period [20,21]. Both 
experimental wave tank testing and numerical modeling are the most common and powerful approaches utilized during the design and development of a wave energy converter [22]. OWC devices have been extensively examined through theoretical, numerical, and experimental studies. It should be noted that physical testing is expensive and may require several trials before reaching the final model design [23, 24], but wave tank experiments with smallscale models with controlled ideal environmental conditions are an important step in wave energy converter development.

Australia has a large wave energy resource which is one of the largest worldwide [25]. By 2020, wave energy could potentially generate about $10 \%$ of Australia's renewable energy [26-28]. Recently, the New South Wales (NSW) government has upgraded many ports and jetties. These locations would be good places to deploy WECs. To address this, a four-chamber small-scale OWC prototype was constructed at the University of Technology Sydney.

This proposed device planned to be part of the new port and jetties structure. The design of this model was the outcome of several years of research and development [29]. The first design was built and tested at the University of Glasgow in 2003, it was three-chambers OWC device $[30,31]$. The model concept was verified, and a mathematical model was developed to describe the device's hydrodynamic performance. In 2012, Hsieh et al. [32] constructed and studied a wall-mounted OWC smallscale model. This had two chambers each with a Savonius turbine which were mechanically linked together. After a few years, a different arrangement using a four-chamber OWC arrangement was tested in a wave tank under regular wave conditions [33]. Further development stages for this prototype were discussed in Ref. [20].

Although the previous $\mathrm{MC}$-OWC studies gave an insight of the device operation, the impacts of the PTO damping on airflow rates, air pressure, inner chamber water surface elevation, and device capture width ratio during varying wave conditions have not been fully addressed. The work reported here developed existing knowledge by investigating the omissions in previous studies and presenting explanations of the wave period, wave height, PTO damping effects on MC-OWC operation using an experimental approach.

\section{Experiments}

\subsection{Experimental Setup and Test Conditions}

The manly hydraulic laboratories (MHL) wave tank in NSW, was utilized for the study, and this is shown in Figure 1. It has a length of $30 \times 10^{3} \mathrm{~mm}$, a width of $1000 \mathrm{~mm}$, and $1.8 \times 10^{3} \mathrm{~mm}$ depth. The testing area of the tank is about $0.7 \mathrm{~m}$ long, which is $15 \mathrm{~m}$ from the wave-making paddle. The flap-paddle wave-maker uses an electrical actuator situated at the left end of the tank. The wavemaker can generate irregular as well as regular waves. The wave height at a maximum is $0.35 \mathrm{~m}$ with a maximum depth of $1.3 \mathrm{~m}$ for wave periods in the range of 0.75 to 3.0 $\mathrm{s}$. There is a beach at the right of the tank which absorbs

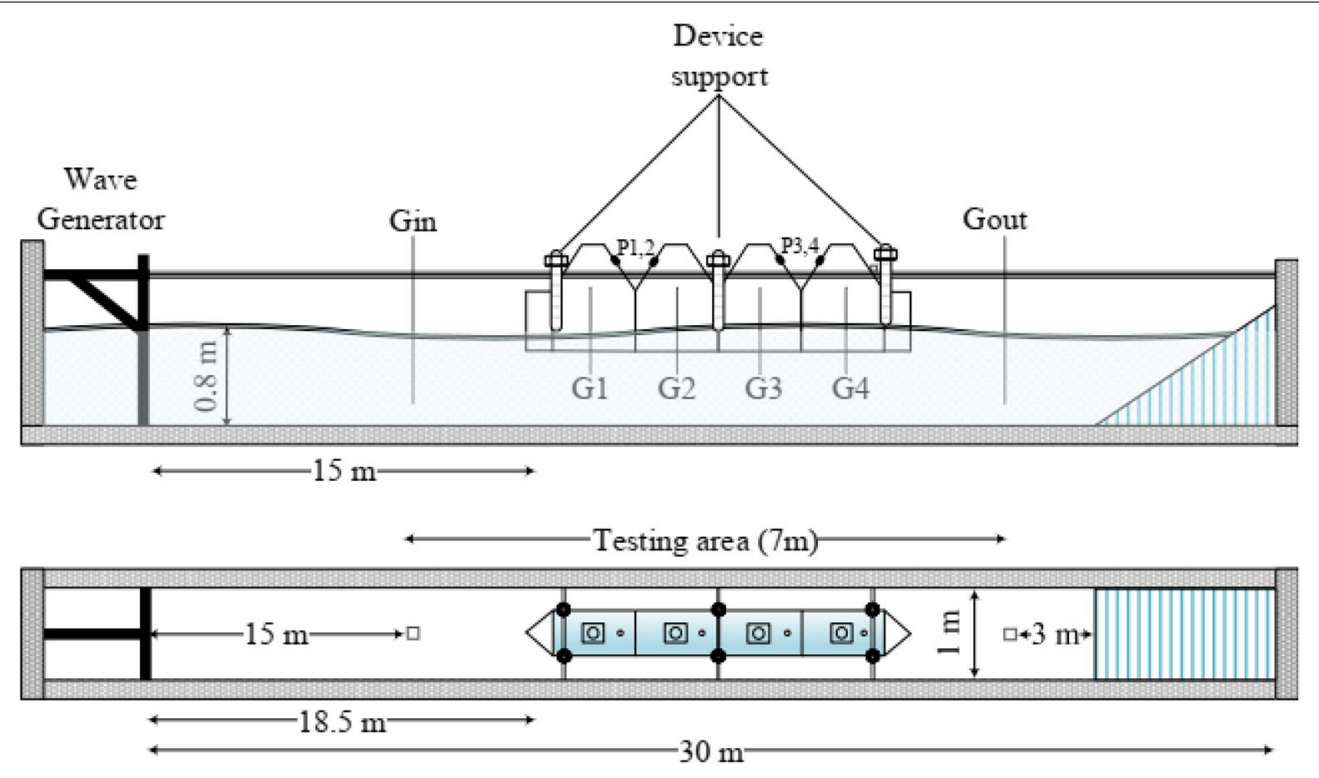

Figure 1 Front and top views of the experimental setup (not drawn to scale) 
the wave energy to keep wave reflection to a minimum. It is formed from several layers of sponge and hollow bricks.

In this study, 198 tests were performed under regular wave conditions involving eleven wave periods in steps of $0.1 \mathrm{~s}$, two wave heights, three orifice diameters, and three draught values. A summary of all test conditions is listed in Table 1 . The water depth $h$ was set to $800 \mathrm{~mm}$. The steepness of the waves steepness ranged over 0.010 and 0.032 for the conditions set. Measurements were taken over a $50 \mathrm{~s}$ time period for all gauges.

Figure 1 shows the experimental arrangement with the data collecting gauge locations illustrated. The distance from the wave paddle to the MC-OWC is $15 \times 10^{3} \mathrm{~mm}$. This is greater than two wavelengths [34]. This ensures that the MC-OWC experiences have fully developed waves across it for all the wave frequencies.

\subsection{MC-OWC Geometry}

The scaling of the model was done using Froude's similitude law $\lambda=1: 16$ scale factor was used. This means that an $800 \mathrm{~mm}$ water depth represents $12.8 \times 10^{3} \mathrm{~mm}$ fullscale depth with a scale length of $3 \times 10^{3} \mathrm{~mm}$ for the model representing $48 \times 10^{3} \mathrm{~mm}$ for a full-scale device

Table 1 Test conditions

\begin{tabular}{llll}
\hline $\begin{array}{l}\text { Orifice } \\
\text { diameter }\end{array}$ & $\begin{array}{l}\text { Draught } \\
\boldsymbol{d}(\mathbf{m m})\end{array}$ & $\begin{array}{l}\text { Wave height } \\
\boldsymbol{H}(\mathbf{m m})\end{array}$ & $\begin{array}{l}\text { Wave period } \\
\boldsymbol{T}(\mathbf{s})\end{array}$ \\
\hline 30 & 200 & 50 & $1.0-2.0$ \\
& 250 & 100 & \\
& 300 & 50 & $1.0-2.0$ \\
40 & 200 & 100 & \\
& 250 & & $1.0-2.0$ \\
60 & 300 & 50 & \\
& 200 & 100 & \\
& 350 & & \\
& 300 & & \\
\hline
\end{tabular}

Note: Based on the water depth and test wave conditions, the wavelength is calculated based on intermediate water length. Dimensions for the model are shown in Figure 2; it was fabricated using glue from $10 \mathrm{~mm}$ Perspex sheets. The dimensions of the Perspex chambers are shown in Figure 2.

Incoming waves were dispersed about the device using two galvanized steel triangular sheets. These reduced the wave reflection. They were fixed to $\mathrm{Ch}-1$ (the first chamber) and Ch-4 (the final chamber), as shown in Figure 3(a); it also illustrates that the device is a side-mount device on the tank's sidewall. This was done with three horizontal rectangular sections, which were fixed using clamps to the tank sidewalls, as shown in Figure 3(b). Each section had two rods threaded for adjustment to keep the model straight and the draught at the desired value. This is illustrated in Figure 3(c). The power take-off system was simulated using a circular orifice located at the top of the chambers, as shown in Figure 3(d).

\subsection{Instrumentation and Measurement \\ 2.3.1 Wave Height Measurement}

The length of the chamber $(L c)$ to shortest wavelength $(L)$ ratio was 0.24 , which should eliminate sloshing modes $(L c=L)$ [35]. Each chamber had a centre located wave gauge to measure the water free surface oscillation $\eta$ $(L c=2, b=2)$ (G1-G4: C-Series Core Sensor, CS) as shown in Figure 1. These gauges had a $5 \mathrm{~mm}$ diameter magnetic float level transmitter with a $25 \mathrm{~mm}$ stroke length. The induced voltages from these undergo $1500 \mathrm{~Hz}$ (period of $0.6 \mathrm{~ms}$ ) digitization. $\eta$ was obtained using the relationship $\eta=\delta \times V(t)$ where $\delta$ is set by the wave gauge static calibration. Additional two-wave gauges (Gin, Gout, model: G-Series) were placed $300 \mathrm{~mm}$ from the front and back faces of the device to measure the incoming and transmitted wave heights. All the wave gauges were calibrated manually at the beginning of each test as per the manufacturer's instructions.

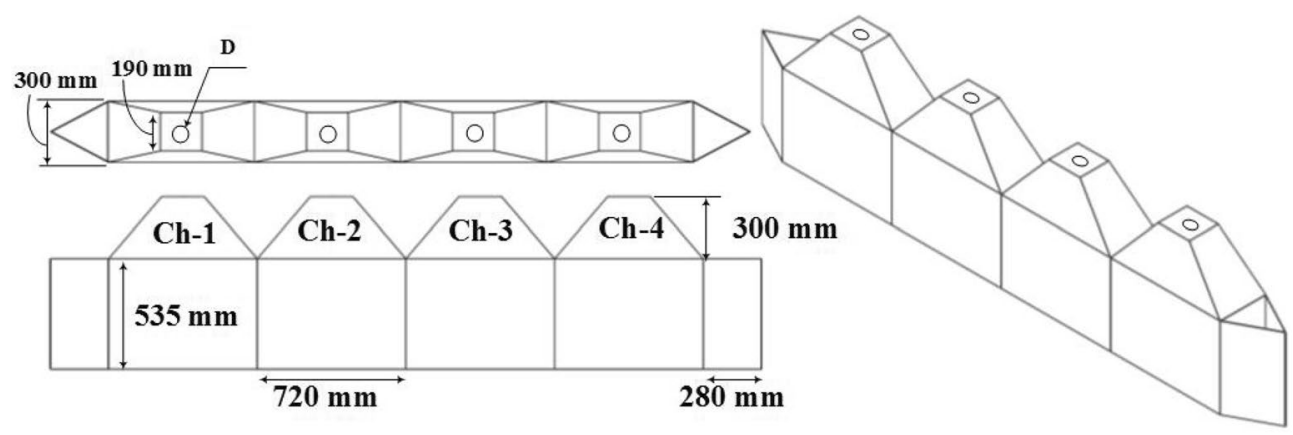

Figure 2 MC-OWC device shape and dimensions 

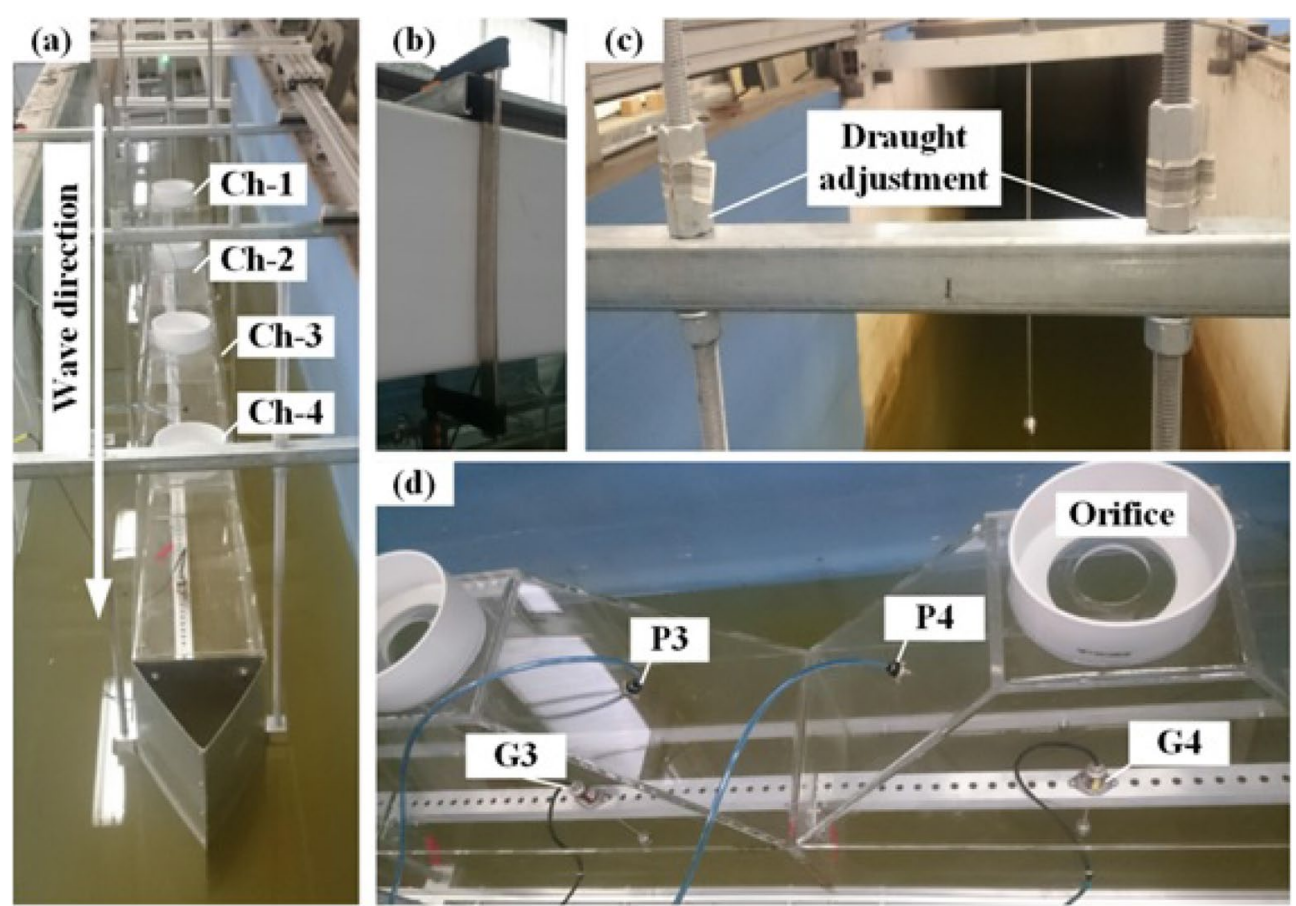

Figure 3 Views of wave flume and physical model in wave flume

\subsubsection{Pressure Measurement}

The differential air pressure (the difference between the air pressure inside the chamber, $p_{c}$, and the atmospheric pressure, $p_{\text {atm }}$ fluctuation inside the OWC chamber is the most significant parameter in estimating an OWC device performance. The pressure inside the chamber is usually measured at a single point $[36,37]$. A single differential pressure transmitter $\left(\mathrm{P}_{1}-\mathrm{P}_{4}\right)$, (model: 616-20B, accuracy $\pm 0.25 \%$ full-scale (F.S) with a range of \pm 10 inch water column (in.w.c)) was used for chamber differential air pressure $(\Delta p)$ measurement as illustrated in Figure 1. All pressure transmitters were calibrated by Fluke 717 Series Pressure Calibrators before the tests. Figure 3(d) illustrates that these were located $10 \mathrm{~mm}$ from the upper edge of the rectangular section in each chamber.

\subsubsection{Calibration of Orifice Plates}

The PTO system in this work was represented by an orifice manufactured using a laser cutting machine. This simulated an impulse turbine. The orifice plate was circular and classified as a thin-walled opening orifice (the ratio between the orifice thickness and orifice diameter was less than 0.5 as given in Refs. $[38,39]$ ). The diameter of the orifices was in range of $0.1<\beta<0.75$ (where $\left.\beta=D_{\text {orifice }} / D_{\text {pipe }}\right)$ as recommended by the International Organization for Standard ISO 5167-2 [40]. Each orifice plate was experimentally calibrated using a Testo 480 IAQ Measurement Kit to determine its Coefficient of Discharge $\left(C_{d}\right)$ according to the ISO 5167-2 standard. The apparatus used in this calibration is illustrated in Figure 4. This shows two pressure taps normally located at a distance of $D_{\text {pipe }}$ and $0.5 D_{\text {pipe }}\left(D_{\text {pipe }}\right.$ is the pipe's internal diameter $=150 \mathrm{~mm}$ ) upstream and downstream of the

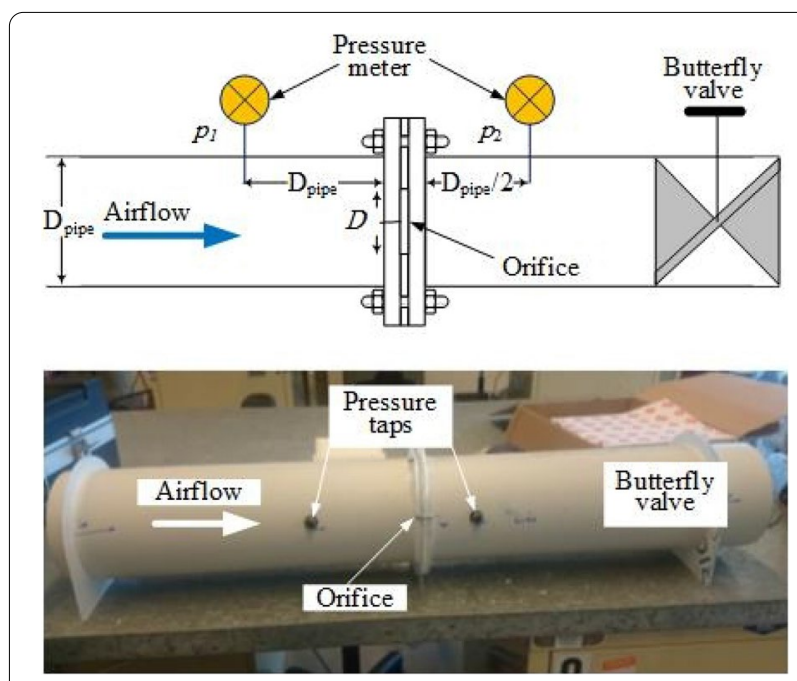

Figure 4 Orifice calibration test rig 
orifice, respectively [40]. These two taps are connected to Dwyer 477AV-0 handheld digital manometer to measure the differential pressure $\left(p_{2}-p_{1}\right)$. The apparatus includes a butterfly valve that can be used to adjust the airflow rate $(Q)$. The atmospheric pressure and temperature during the calibration were measured to be $94 \mathrm{kPa}$ and $22{ }^{\circ} \mathrm{C}$, respectively. The dry air density, $\rho_{\text {air }}$, at this temperature was taken as $1.2 \mathrm{~kg} / \mathrm{m}^{3}$. The calibration was conducted by changing the airflow rate, and a series of pressure drops across the orifice plate was measured. The orifice $Q$ airflow rate $\left(\mathrm{m}^{3} / \mathrm{s}\right)$ can be obtained from standard orifice theory using Eq. (1).

$$
Q=C_{d} A_{2} \sqrt{\frac{2|\Delta p|}{\rho_{\text {air }}}}
$$

where the opening area of the orifice is $A_{2}$, and the differential air pressure is $\Delta p$. Under known pressure and airflow rate, Eq. (1) was applied to determine the $C_{d}$, which was estimated to be $C_{d}=0.597$.

\subsection{Data Logging and Analysis}

The data acquisition system $(\mathrm{I} / \mathrm{O})$ is utilised to collect the raw data from the sensors at a sampling rate of $10 \mathrm{~Hz}$. To prevent waves reflection from the wave paddle, the window period for data collection was set at $50 \mathrm{~s}$. The pressure transmitter and wave gauge data are raw data logged using a data acquisition system and transformed using calibration coefficients into usable measurements. The wave energy $\left(P_{i n}\right)$ per unit width of wave propagation (wave energy flux) can be obtained from Eq. (2) [41]:

$$
P_{\text {in }}=\frac{\rho g H^{2} L}{16 T}\left(1+\frac{2 k h}{\sinh (2 k h)}\right),
$$

where $\rho$ is the fluid density, $g$ is gravitational acceleration $9.8 \times 10^{3} \mathrm{~mm} / \mathrm{s}^{2}, L$ is the wavelength, $T$ wave period, $h$ is water depth $(h=0.7 \mathrm{~m})$, and $k$ is the wavenumber $(k$ $=2 \pi / \mathrm{L}$ ).

\section{Results and Discussion}

\subsection{Regular Wave Tests}

The primary reason for the experimental work is to assess the influence of incident wave height, wave period, and damping from the PTO on the parameters that control the MC-OWC performance. These are pneumatic power $P_{n}$, airflow rate $Q$, chamber water surface elevation $\eta$, and differential air pressure $\Delta p$.

One of the critical parameters that influence the device's performance is device draught. More details have been presented in Ref. [20]. This parameter could tune the device to a range of wave conditions, improving the proposed model's performance.

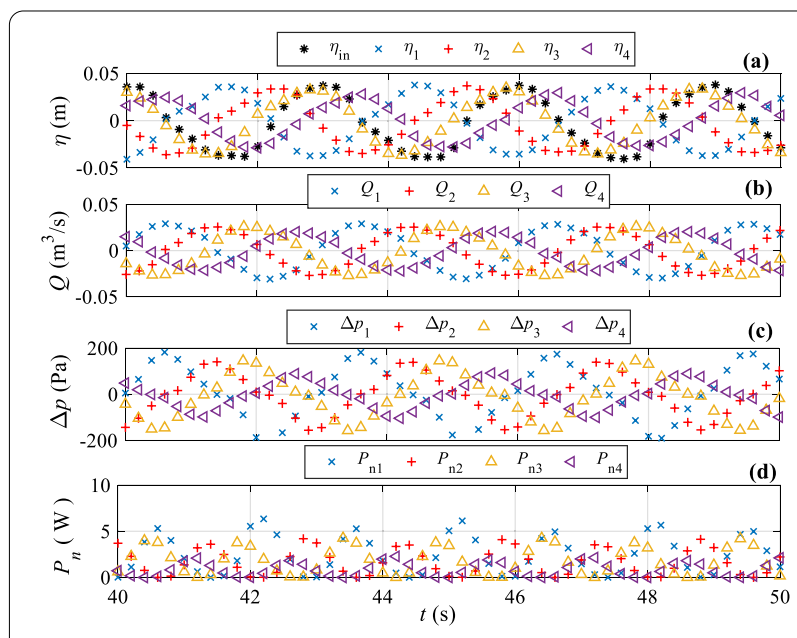

Figure 5 Sample of time-series data of (a) water surface elevation $\eta$, (b) airflow rate through the orifice $Q$, (c) differential air pressure $\Delta p$, (d) pneumatic power $P_{n}$ in each chamber for a wave condition of $H$ $=100 \mathrm{~mm}, T=1.5 \mathrm{~s}$, a draught $d=250 \mathrm{~mm}$ and an orifice of $D=60$ $\mathrm{mm}$

Table 2 Orifice diameter and opening ratio

\begin{tabular}{llll}
\hline$D(\mathrm{~mm})$ & 30 & 60 & 80 \\
$R_{i}(\%)$ & 0.34 & 1.35 & 2.40 \\
\hline
\end{tabular}

An example of the time-series measurement of these parameters is shown in Figure 5. In the context of the analysis, the time-averaged extracted pneumatic power $\left(P_{n}\right)$ and the hydrodynamic efficiency (or capture width ratio; $\varepsilon$ ) were calculated from Eqs. (3) and (4), respectively.

$$
\begin{aligned}
& \overline{P_{n}}=\frac{1}{T} \int_{0}^{T} Q(t) \times \Delta p \mathrm{~d} t, \\
& \varepsilon=\frac{\bar{P}_{n}}{b \times P_{i n}} .
\end{aligned}
$$

The airflow rate through the PTO was calculated using Eq. (1). The three different orifice plates used in this test to introduce different damping factors were characterized by the orifice opening ratio $\left(R_{i}\right)$, which is defined as the opening area of the orifice $\left(A_{2}\right)$ divided by the cross-sectional area of the OWC chamber $\left(A_{1}\right)$ as summarised in Table 2. 


\subsection{Wave Height and Period Effects}

The results of two different wave heights $H=50$ and $100 \mathrm{~mm}$ over a range of wave periods $T=1.0-2.0 \mathrm{~s}$ (see Table 1). This was with an orifice opening ratio $R_{2}=1.35 \%$ and a draught of $d=250 \mathrm{~mm}$. The effects of wave period and height on the water surface elevation $\eta$, the airflow rate $(Q)$, the pneumatic power $P_{n}$ and the differential air pressure $\Delta p$ are shown in Figure 6. It can be seen that between the four chambers, the highest performance was observed in the first chamber. In contrast, the performance gradually decreased up to the fourth chamber.

This could be assigned to the energy absorbed by each chamber and the energy lost in each chamber, which reduces the available energy at the fourth chamber that can be absorbed [42, 43]. The results in Figure 6 illustrate that each performance parameter has a similar trend for both wave heights, but increasing the wave height increases the absolute values of each parameter tested. This may be due to increasing energy content in the larger wave height.

An example of this effect is summarised in Table 3, where the ratio between the average results is shown over the whole period range tested $(1.0-2.0 \mathrm{~s})$ for $H=100 \mathrm{~mm}$ and $H=50 \mathrm{~mm}$. These results show that the four chambers have similar responses to increasing the wave height. For each chamber, it is known that changing the wave period has a significant effect on device interaction with incoming waves; it affects different energy components such as reflected energy, transmitted energy, and energy
Table 3 Effect of increasing wave height from $50 \mathrm{~mm}$ to 100 $\mathrm{mm}$ on device performance parameters (presented as a ratio)

\begin{tabular}{lllll}
\hline Parameter & $\mathbf{C H}-\mathbf{1}$ & $\mathbf{C H}-\mathbf{2}$ & $\mathbf{C H}-\mathbf{3}$ & $\mathbf{C H}-\mathbf{4}$ \\
\hline$\eta_{H 100} / \eta_{H 50}$ & 1.56 & 1.59 & 1.59 & 1.55 \\
$Q_{H 100} / Q_{H 50}$ & 1.51 & 1.57 & 1.56 & 1.58 \\
$\Delta p_{H 100} / \Delta p_{H 50}$ & 2.37 & 2.49 & 2.47 & 2.51 \\
$P_{n H 100} / P_{n H 5}$ & 4.25 & 4.10 & 4.13 & 4.21 \\
\hline
\end{tabular}

losses $[44,45]$. This, in turn, impacts the device's performance. Figure 7 illustrates the effects in terms of the timeseries results of the performance parameters. These are for an orifice opening ratio $R_{2}$ of 0.0135 with a constant wave height $H$ of $0.05 \mathrm{~m}$ and a draught $d$ of $0.25 \mathrm{~m}$.

The overall performance of an OWC device can be assessed using its capture width ratio $(\varepsilon)$ as given by Eq. (4). Figure 8 illustrates the capture width ratio for each chamber $\left(\varepsilon_{c}\right)$ in the MC-OWC device when subjected to a wave height $H=50 \mathrm{~mm}$. As can be seen, the maximum capture width ratio for all chambers (Ch-1 to $\mathrm{Ch}-4)$ was achieved at about $T=1.3 \mathrm{~s}$ wave period, and this ratio was 0.77 in Ch-1, 0.54 in Ch-2, 0.44 in Ch-3, and 0.32 in $\mathrm{Ch}-4$. The drop in the capture width ratio from $\mathrm{Ch}-1$ to Ch-4 follows the drop in the pneumatic energy, as shown in Figure 6 (4th row). This assumes that the chambers have an incident wave energy that is constant. The capture width ratio reported in this study, especially $\mathrm{Ch}-1$, is quite a lot larger than found experimentally for a typical single

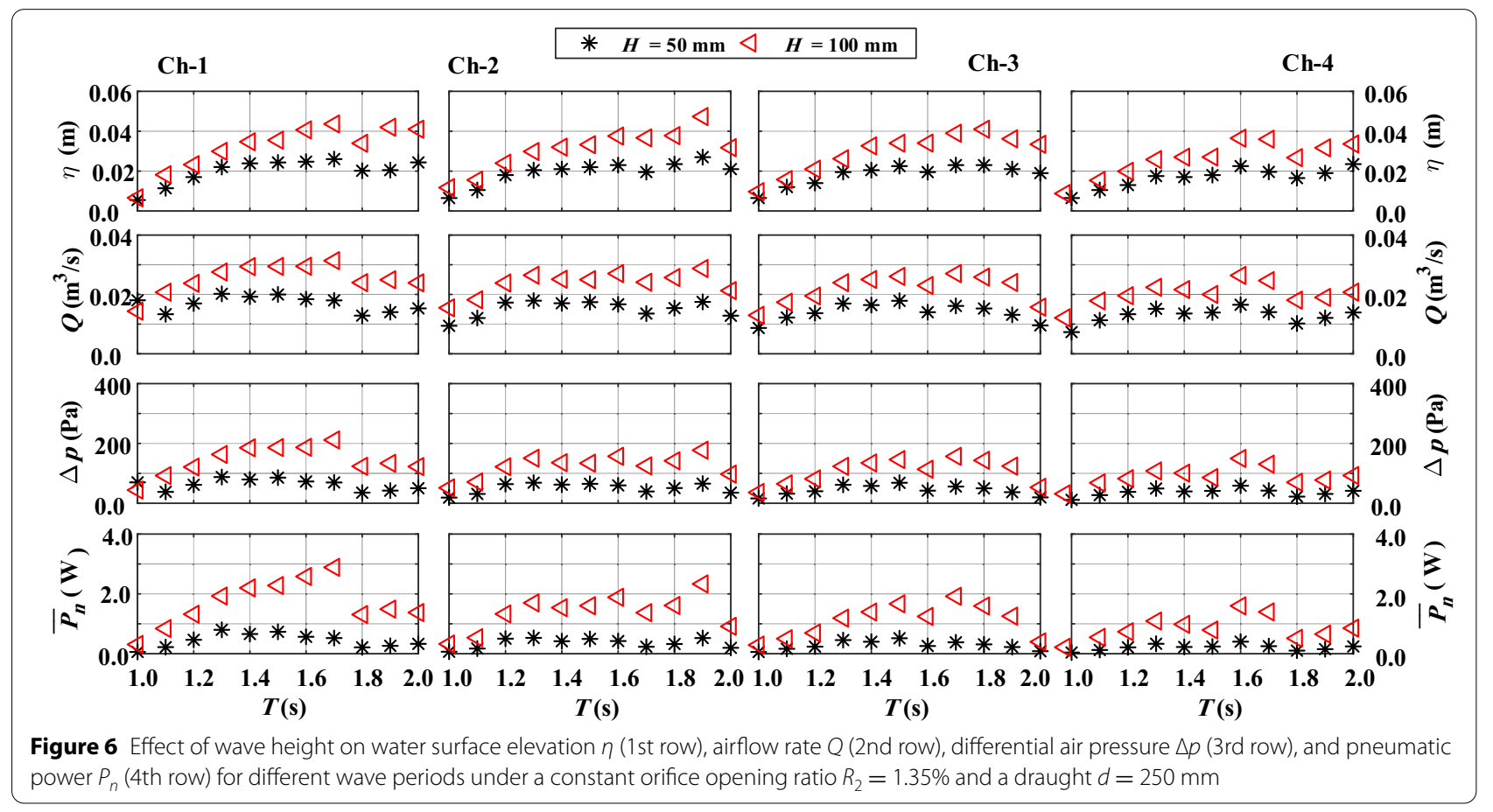



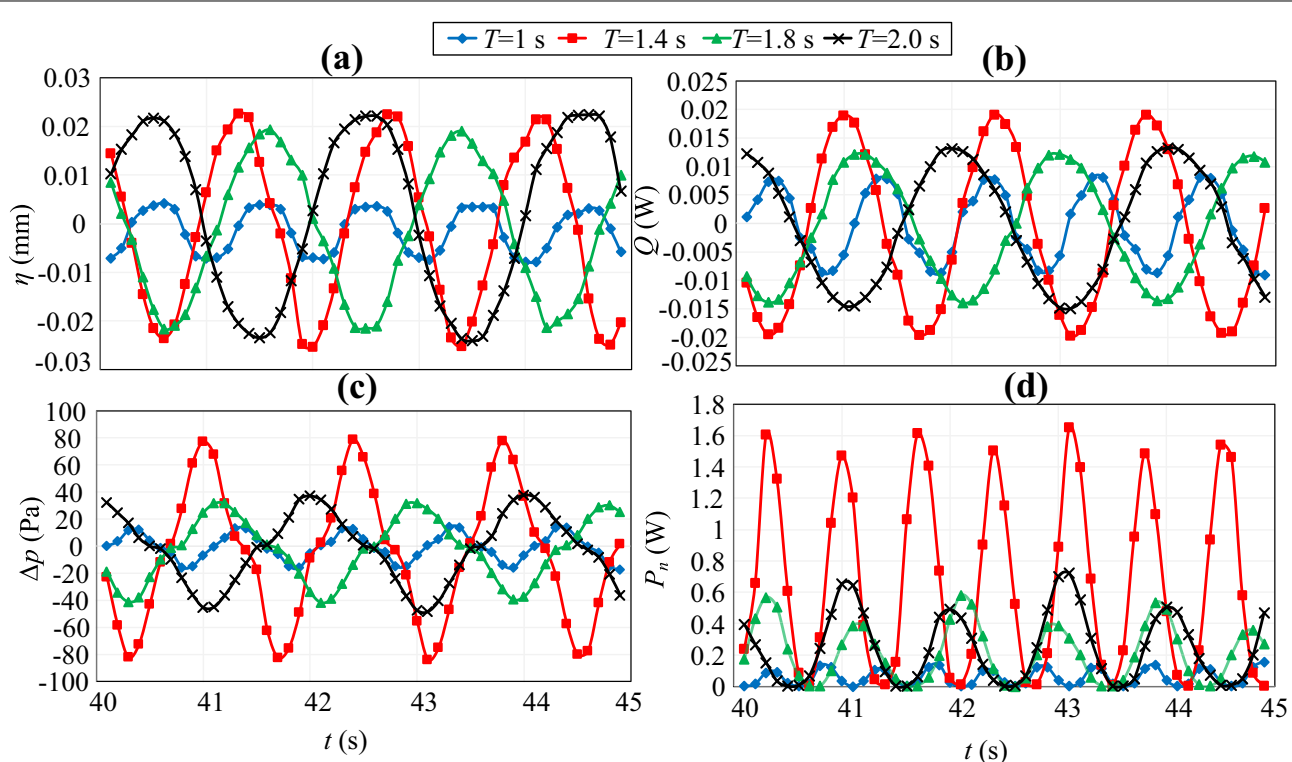

Figure 7 Sample time-series data of: (a) the water surface elevation $\eta_{\text {, }}(\mathbf{b})$ airflow rate $Q$, (c) the differential air pressure $p$, and (d) and the pneumatic power $P_{n}$ in the first chamber over four different wave periods at a constant wave height $H=50 \mathrm{~mm}$ and an opening ratio $R_{2}=1.35 \%$
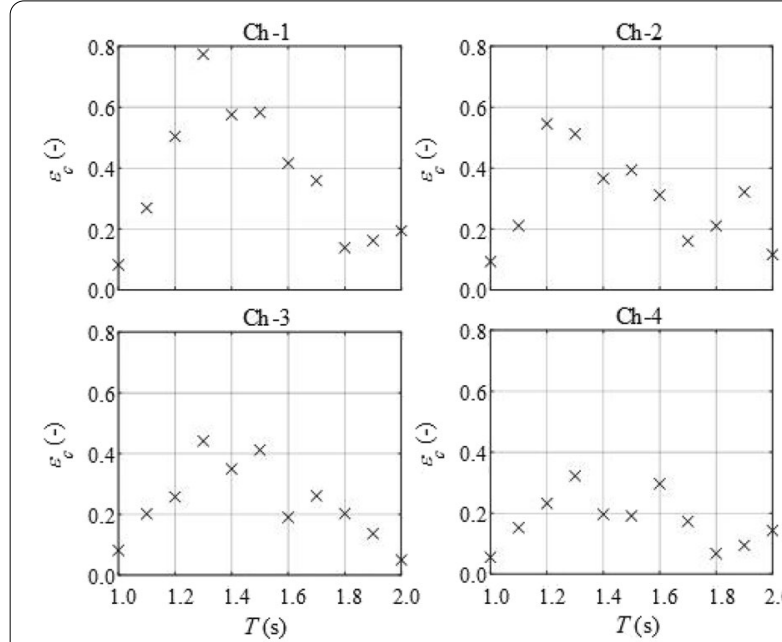

Figure 8 Capture width ratio $\left(\varepsilon_{c}\right)$ for each chamber of the MC-OWC device at a constant wave height $H=50 \mathrm{~mm}$, a device draught $d=$ $250 \mathrm{~mm}$ and an orifice opening ratio $R_{2}=1.35 \%$

chamber OWC device with a symmetrical vertical plane; i.e., there is an identical draught for the front and rear lips $[42,46-48]$.

For example, using 2D wave flume experiments for an OWC device with a single chamber, the work in Ref. [48] found the maximum capture width ratio was 0.35 , which is lower than the first chamber maximum capture width ratio of the model tested in this study [47] tested an offshore-stationary OWC in 3D. This provided a maximum capture width ratio of about 0.26 ; this is even lower than the capture width ratio for $\mathrm{Ch}-4(0.32)$ of the MC-OWC model considered here.

During the early stage of research and development of such MC-OWC devices, Ref. [46] tested a three-chamber MC-OWC and reported a maximum total capture width ratio of 1.07 , which is about $39 \%$ less than the maximum value achieved with the first three chambers of the current device [32] developed a two-chamber MC-OWC model and found a maximum total capture width ratio of 0.93 , which is about $29 \%$ less than the value captured by Ch- 1 and Ch- 2 of the model tested herein. This difference could be related to the setup of Refs. [32, 46] experiments where the devices were mounted on the tank sidewall; therefore, the devices were only capable of harvesting the incident energy from underneath the front lip and one sidewall of the device. A more closely related work to the present model is the Seabreath that has a total capture width ratio of 0.92 [49]. Recently, $\mathrm{He}$ et al. [42] proposed a box-type breakwater and floating with two OWC chambers. This was tested and shown to provide a maximum capture width ratio of about 0.36 . The majority of this value comes from the front chamber $\left(\varepsilon_{c}=0.31\right)$ which is, in total, about half the value captured by Ch- 1 of the model investigated here.

Figure 9 illustrates the impact of wave period and height have on the MC-OWC device total capture width ratio $\varepsilon$ with an opening ratio $R_{2}=1.35 \%$ and constant device draught $d=0.25 \mathrm{~m}$. The results demonstrate that there was an initial increase in $\varepsilon$ as the wave period increased 


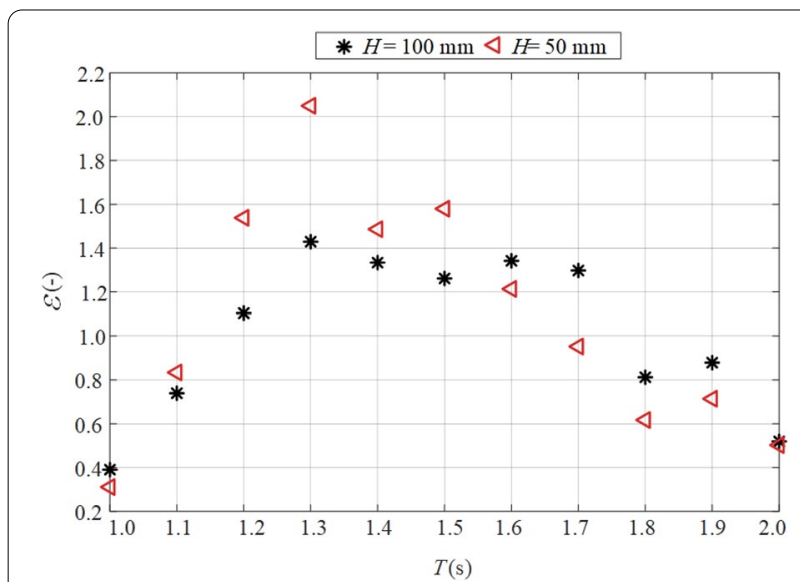

Figure 9 Effect of wave height on the total capture width ratio $(\varepsilon)$ of the MC-OWC device for different wave periods at a constant device draught $d=250 \mathrm{~mm}$ and an opening ratio $R_{2}=1.35 \%$ until the resonant period peaked at $T=1.3 \mathrm{~s}$; then, as the wave period further increased, $\varepsilon$ reduced. When $H=0.05$ $\mathrm{m}$, there is a maximum for the total capture width ratio $(\varepsilon)$ of 2.1 at $T=1.3 \mathrm{~s}$. This peak value decreases to 1.4 at the same resonant period when the wave height $H$ doubles to $0.1 \mathrm{~m}$. However, over the entire wave period range, a wave height increase from 0.05 to $0.1 \mathrm{~m}$ has inconsistent effects in terms of the capture width ratio such that $\varepsilon$ improves by about 1.1-1.3 times in the long-period testing ( $T>$ 1.6). The larger wave height negatively impacts the shortperiod testing $(T<1.6)$ performance of the device. This results in $\varepsilon$ reducing by $0.70-0.90$ times.
Table 4 PTO damping coefficient $(\tau)$

\begin{tabular}{lccr}
\hline & $\boldsymbol{R}_{\mathbf{1}}$ & $\boldsymbol{R}_{\mathbf{2}}$ & \multicolumn{1}{c}{$\boldsymbol{R}_{\mathbf{3}}$} \\
\hline $\boldsymbol{R}_{i}(\%)$ & 0.34 & 1.35 & 2.40 \\
$\tau\left(\mathrm{kg}^{1 / 2} \mathrm{~m}^{-7 / 2}\right)$ & 1854.6 & 463.7 & 260.8 \\
\hline
\end{tabular}

The improvement in capture width ratio for a longperiod scheme could be due to the extracted pneumatic power significantly increasing at these periods (see the 4th row in Figure 6). Hence, with increasing wave height, the energy losses increase, as explained in the energy balance analysis for a single OWC device presented by Elhanafi et al. [50]. Overall, the higher capture width ratio is shown in Figure 9. This compares with what was reported in previous research, and highlights the effectiveness and significance of the present MC-OWC device.

\subsection{PTO Damping Effect}

The previous sections discussed the results of the tests carried out with one PTO damping value. This section describes the PTO damping influence on the MC-OWC device performance. The experimental work was performed for three alternative orifice diameters, i.e., PTO damping values. The orifice pressure drop $p$ is approximately proportional to the square of the airflow rate. This is validated for each orifice using a damping coefficient $(\tau)$. This coefficient $\tau$, is considered a key controlling factor for the OWC capture width ratio [21, 51]. This can be computed using Eq. (5).

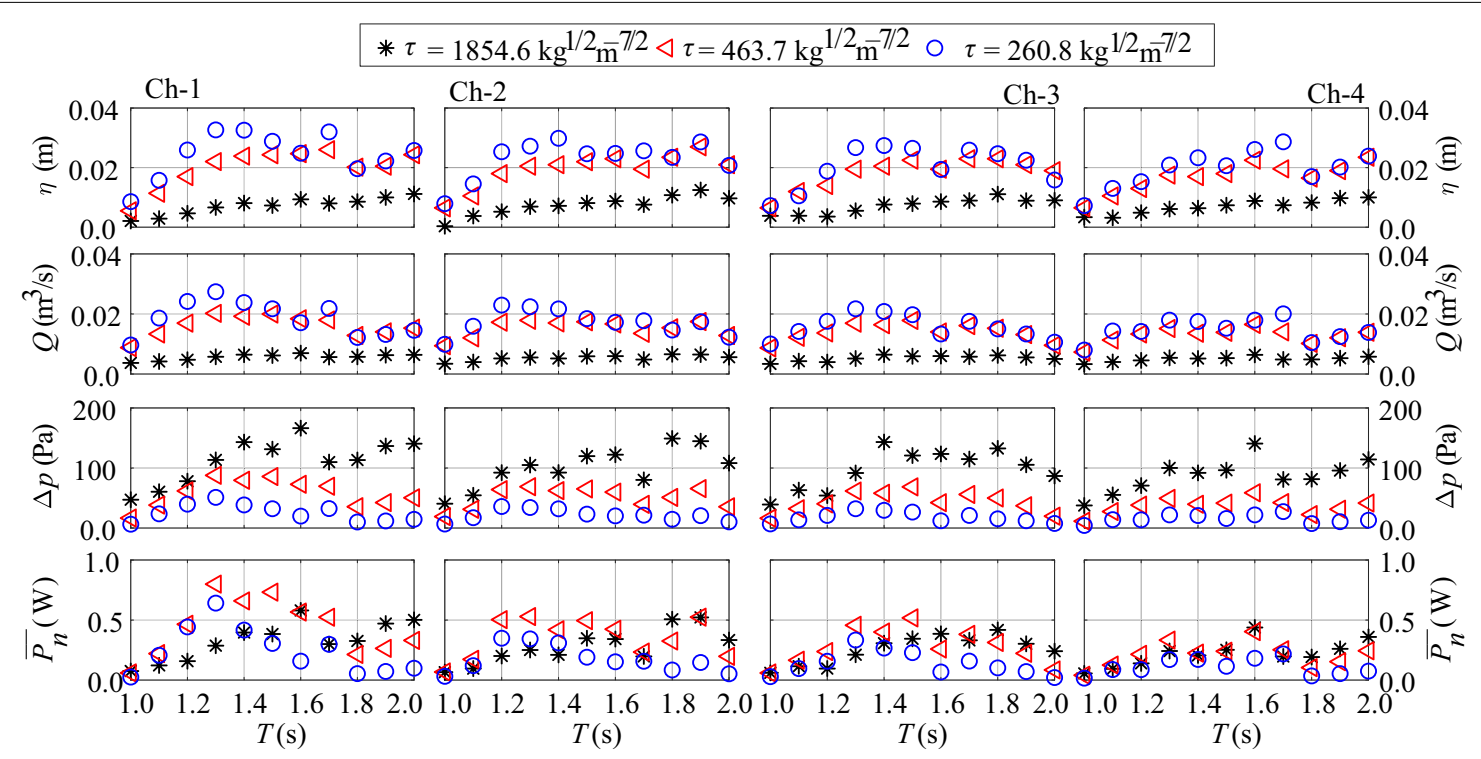

Figure 10 Impact of PTO damping on the water surface elevation $\eta$ (1st row), airflow rate $Q$ (2nd row), the differential air pressure $p$ (3rd row), and the pneumatic power $P_{n}$ (4th row) at constant wave height $(H=50 \mathrm{~mm})$ and device draught $(d=250 \mathrm{~mm})$ over the wave period listed in Table 1 
Table 4 gives the values of the damping coefficients used in this study.

In order to better assess the impact that the PTO damping has on the performance parameters $(\eta, p$, and $Q)$, Figure 10 shows the variation of these parameters for all the damping coefficients considered in these tests at a wave height $H=50 \mathrm{~mm}$. Overall, it is clear that PTO damping has a similar effect on the performance parameters of every chamber. Figure 10 (1st row) shows that the inner free surface elevation of each chamber $\eta$ decreases as the damping coefficient increases. For instance, $\eta$ decreases from $0.035 \mathrm{~m}$ in Ch-1 at $T=1.3 \mathrm{~s}$ to just about $0.01 \mathrm{~m}$ at the same wave period when $\tau$ increases from 260.8 to $1854.6 \mathrm{~kg}^{1 / 2} \mathrm{~m}^{-7 / 2}$. The airflow rate $Q$ is a function of the free surface vertical velocity $V_{\mathrm{z}}$ (given in-compressible flow). This is computed from the time differential of the free surface elevation $\eta$ where $V_{z}=\mathrm{d} \eta / \mathrm{d} t$. The airflow rate should follow the changes in $\eta$. This correlation is illustrated in the results in Figure 10 (2nd row); it can be seen that $Q$ has the same trend of $\eta$ in all chambers. This is with maximum and minimum values of about 0.03 and 0.005 $\mathrm{m}^{3} / \mathrm{s}$, respectively, in Ch-1 at $T=1.3 \mathrm{~s}$. These correlate with the results reported in previous research $[44,52,53]$, which focused on single chamber OWC devices. However, Figure 10 (3rd row) illustrates that the differential air pressure $(p)$ had an opposite trend to the airflow rate $(Q)$, such that $p$ gradually increases. For example, Ch- 1 has a minimum of $20 \mathrm{~Pa}$ and rises to a maximum of $166 \mathrm{~Pa}$ at $T$ $=1.6 \mathrm{~s}$ with an increasing damping coefficient. The pneumatic power $P_{n}$ is a function of both $p$ and $Q$; the results in Figure 10 (4th row) illustrate a certain damping value of $463.7 \mathrm{~kg}^{1 / 2} \mathrm{~m}^{-7 / 2}$ where $P_{n}$ is maximum. The maximum values decreased from $0.8 \mathrm{~W}(\mathrm{Ch}-1)$ to $0.4 \mathrm{~W}(\mathrm{Ch}-4)$ at $T$ $=1.3 \mathrm{~s}$.

$$
\tau=\frac{\sqrt{\Delta p}}{Q}
$$

The device capture width ratio depends on the PTO damping that the turbine has on the system and the wave conditions. To quantify this influence, Figure 11 illustrates the impact of three different PTO damping values on the $\varepsilon$ of the MC-OWC model when subjected to two different wave heights with a constant draught of $d=0.25 \mathrm{~m}$.

Figure 11 illustrates that the maximum capture width ratio shifts to a lower wave period with decreasing PTO damping. Hence, the opening ratio increases from $0.32 \%$ to $2.4 \%$. This is probably due to decreasing resonant period inside the chamber with reducing PTO damping.
This is in line with the numerical and experimental results of onshore and offshore OWC devices reported by [54-56].

Figure 11 shows how important PTO damping is. This can be utilized to maximize the capture width ratio of the device over a certain wave period range. For example, an intermediate PTO damping $\left(R_{2}\right)$ could improve the device capture width ratio for the entire wave period range under both wave heights, but a larger PTO damping $\left(R_{1}\right)$ could be more beneficial for the large-wave period operation, especially for the smaller wave height $H=50 \mathrm{~mm}$.

\section{Conclusions}

This work has addressed the MC-OWC wave energy converter device composed of four fixed rectangular OWC chambers. This device was considered as a direct complement for the development of MC-OWC devices towards full-scale deployment. A set of tests on a physical model were conducted to investigate the impact of the following aspects on the model performance: (1) the wave conditions including period and wave height for regular waves, and (2) PTO damping representing the damping exerted by the turbine on the OWC motion. The PTO damping was modeled by varying orifice (circular opening) diameters, with each diameter corresponding to a damping coefficient.

From the results discussed, the following main points can be made. The influence of the PTO damping on the system is a key factor that has the greatest influence on the device performance. The chamber pressure is higher when the PTO damping increases. There is also lower free surface motion and lower airflow rate for all the incident wave periods with increasing PTO damping. The wave period at which the peak capture width ratio occurs was found to reduce as the PTO damping decreases. Furthermore, among the three damping values tested, the intermediate with an orifice opening ratio $R_{2}=1.35 \%$ was found to be the optimum damping that can maximize the capture width ratio for all chambers over all the regular wave conditions tested.

Incident waves can pass both underneath and around the OWC chamber sidewalls with the design of the model tested. Therefore, the maximum capture width ratio obtained was 2.1 under regular wave conditions. These values were the highest among all similar concepts that have been reported in previous research. This improvement in the capture width ratio is deserving of further investigation under more realistic irregular wave conditions. 


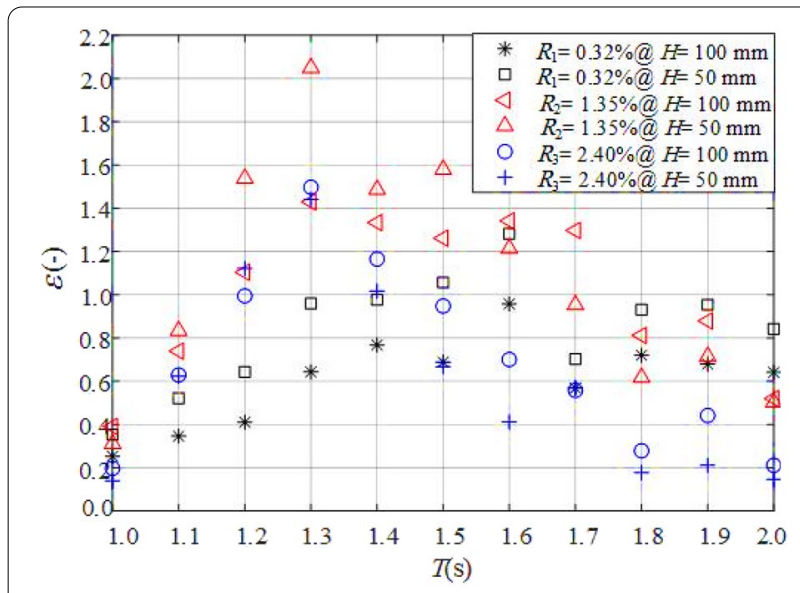

Figure 11 The impact of three orifice opening ratios (PTO damping) and two wave heights on the total capture width ratio $(\varepsilon)$ under constant draught $d=250 \mathrm{~mm}$

\section{Appendix}

Experiment Uncertainty and Repeatability Analysis

The uncertainty analysis performed for these experiments is in accordance with the International Organization for Standardization (ISO) Guide for the Expression of Uncertainty in Measurement [57], also called GUM. This method was adopted by the International Towing Tank Conference (ITTC) [58, 59]. According to the ISO (2005), experimental uncertainties are categorized into two groups, Type 1 (Random), which is estimated from repeated measurements, and Type B (Systematic), which is estimated using the available information such as the calibration procedure and data provided by the manufacture of each instrument. In the experimental tests performed in this work, excellent experimental repeatability was achieved, and all measurement uncertainties were in the order of $\pm 6 \%$, giving a level of confidence
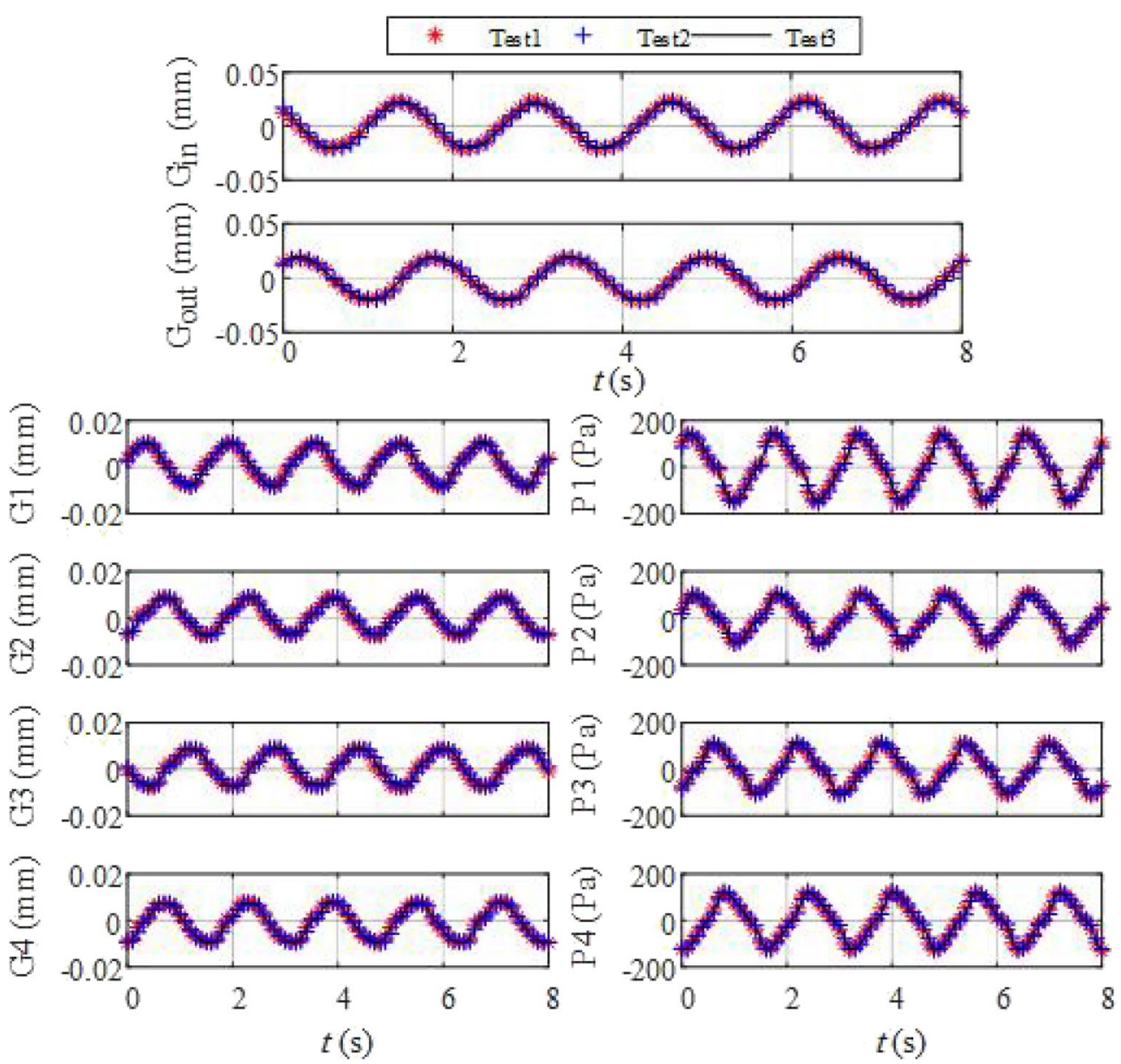

Figure 12 Sample time-series data of the experiment repeatability for a wave condition of $H=50 \mathrm{~mm}, T=1.6 \mathrm{~s}$ and a constant opening ratio of $R_{i}=1.34 \%$ 

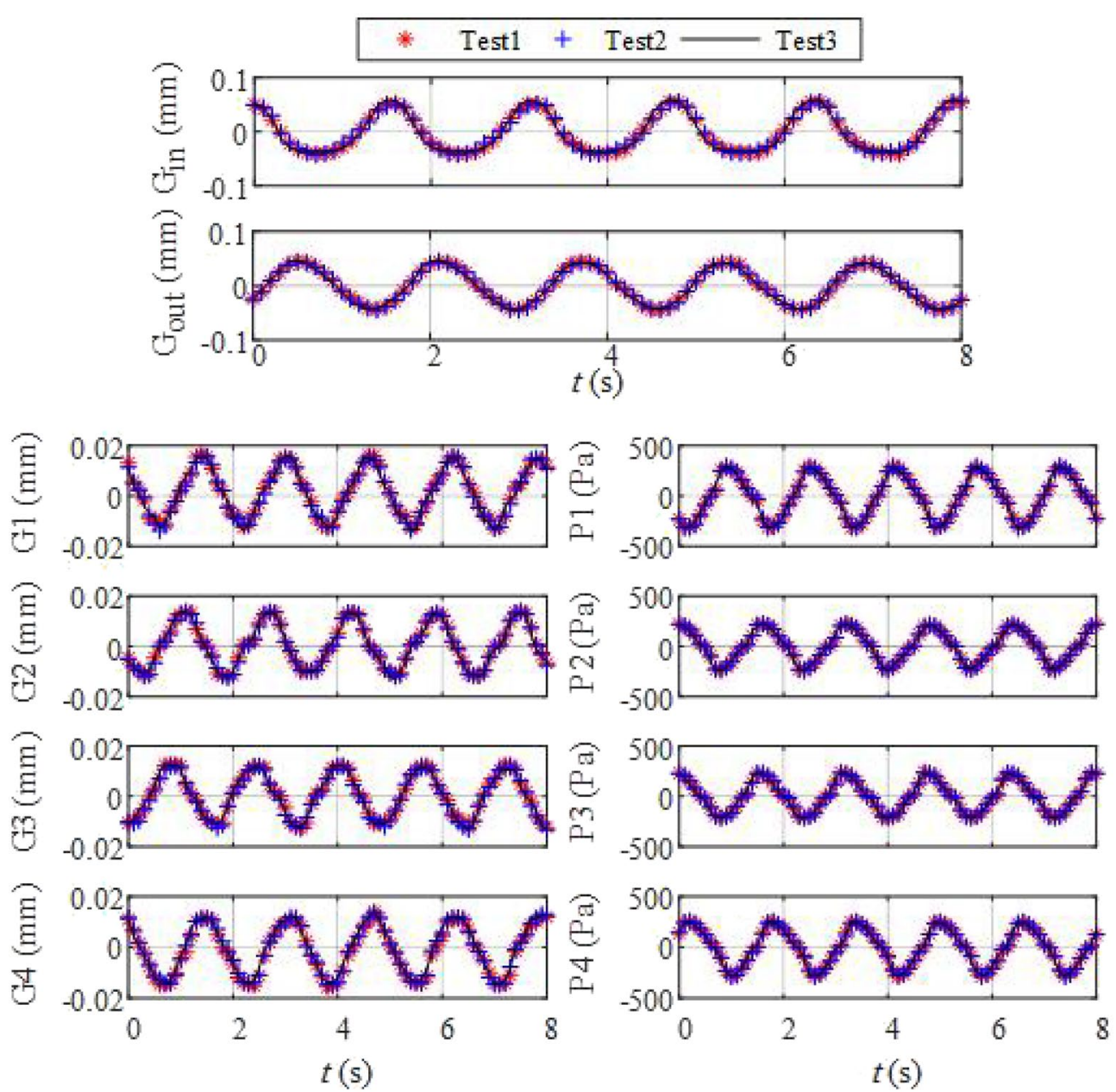

Figure 13 Sample time-series data of the experiment repeatability for a wave condition of $H=100 \mathrm{~mm}, T=1.6 \mathrm{~s}$ and a constant opening ratio of $R_{i}=1.34 \%$

of approximately $95 \%$, as shown in Figures 12, 13, and 14 . These conditions included non-sequentially repeated runs as recommended by ITTC $[58,59]$ to demonstrate experimental repeatability.

Table 5 summarizes the three test uncertainty conditions at a constant opening ratio and fixed device draft.
Table 6 summarises all of the uncertainty analyses for the experiments conducted in this project. US-A is the uncertainty Type A, US-B is the uncertainty Type B, the US is the standard uncertainty, and the expanded uncertainty was listed in the last column in Table 6. 


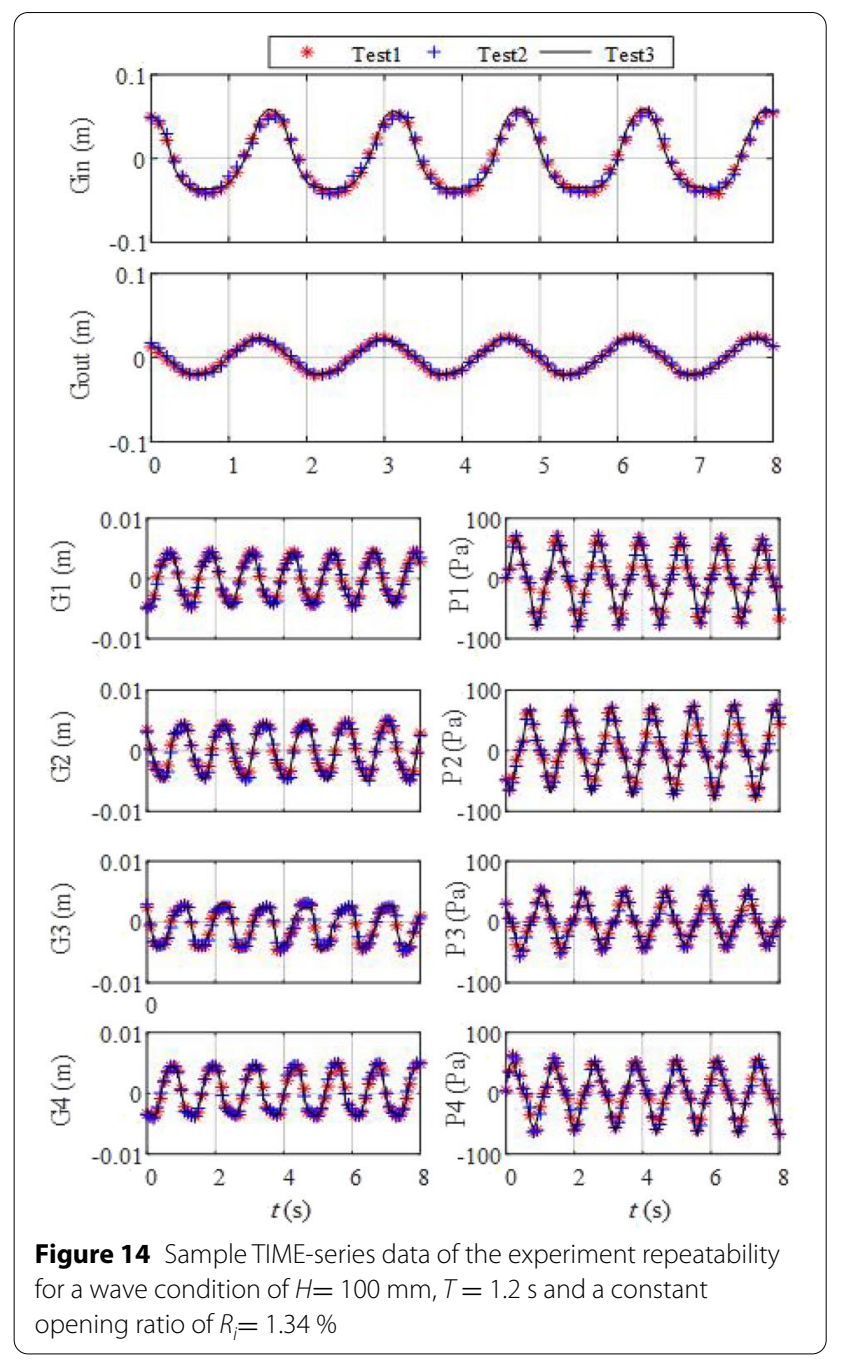

Table 5 Repeatability test conditions

\begin{tabular}{lcl}
\hline Test number & $\begin{array}{l}\text { Wave height } \\
\boldsymbol{H}(\mathbf{m m})\end{array}$ & $\begin{array}{l}\text { Wave period } \\
\boldsymbol{T}(\mathbf{s})\end{array}$ \\
\hline Test 1 & 50 & 1.6 \\
Test 2 & 100 & 1.6 \\
Test 3 & 50 & 1.2 \\
\hline
\end{tabular}

Table 6 Experimental uncertainity

\begin{tabular}{|c|c|c|c|c|c|c|c|}
\hline \multirow[t]{3}{*}{ Instruments } & \multicolumn{2}{|l|}{$2 * U_{S-A}$} & \multicolumn{3}{|c|}{ Standard uncertainity } & \multicolumn{2}{|c|}{$2 *$ Expanded uncertainity } \\
\hline & \multirow[b]{2}{*}{$(H=50 \mathrm{~mm})$} & \multirow[b]{2}{*}{$(H=100 \mathrm{~mm})$} & \multirow[t]{2}{*}{$2 * U_{S-B}$} & \multicolumn{2}{|l|}{ Us } & \multirow[b]{2}{*}{$(H=50 \mathrm{~mm})$} & \multirow[b]{2}{*}{$(H=100 \mathrm{~mm})$} \\
\hline & & & & $(H=50 \mathrm{~mm})$ & $(H=100 \mathrm{~mm})$ & & \\
\hline $\mathrm{G}_{\text {in }}(\mathrm{mm})$ & \pm 0.265 & \pm 0.271 & \pm 0.0020 & \pm 0.265 & \pm 0.271 & \pm 1.140 & \pm 1.166 \\
\hline $\mathrm{G}_{\text {out }}(\mathrm{mm})$ & \pm 0.124 & \pm 0.125 & \pm 0.0420 & \pm 0.131 & \pm 0.132 & \pm 0.563 & \pm 0.567 \\
\hline $\mathrm{G} 1(\mathrm{~mm})$ & \pm 0.008 & \pm 0.008 & \pm 0.1341 & \pm 0.134 & \pm 0.134 & \pm 0.578 & \pm 0.578 \\
\hline $\mathrm{G} 2(\mathrm{~mm})$ & \pm 0.015 & \pm 0.015 & \pm 0.0086 & \pm 0.017 & \pm 0.017 & \pm 0.074 & \pm 0.074 \\
\hline G3 (mm) & \pm 0.011 & \pm 0.011 & \pm 0.0126 & \pm 0.017 & \pm 0.017 & \pm 0.072 & \pm 0.072 \\
\hline $\mathrm{G} 4(\mathrm{~mm})$ & \pm 0.003 & \pm 0.003 & \pm 0.0163 & \pm 0.017 & \pm 0.017 & \pm 0.071 & \pm 0.071 \\
\hline P1 (Pa) & \pm 0.833 & \pm 0.775 & \pm 0.0012 & \pm 0.833 & \pm 0.775 & \pm 3.584 & \pm 3.335 \\
\hline $\mathrm{P} 2(\mathrm{~Pa})$ & \pm 2.087 & \pm 1.443 & \pm 0.0020 & \pm 2.087 & \pm 1.443 & \pm 8.980 & \pm 6.209 \\
\hline P3 (Pa) & \pm 0.549 & \pm 0.662 & \pm 0.0004 & \pm 0.549 & \pm 0.662 & \pm 2.362 & \pm 2.849 \\
\hline $\mathrm{P} 4(\mathrm{~Pa})$ & \pm 1.259 & \pm 0.692 & \pm 0.0041 & \pm 1.259 & \pm 0.692 & \pm 5.418 & \pm 2.978 \\
\hline
\end{tabular}




\section{Acknowledgements}

The authors gratefully acknowledge the technical support during experiments from Mr. Indra Jayewardene, Manly Hydraulics Laboratory MHL, NSW, Australia.

\section{Authors' Information}

Mohammad Shalby, born in 1982, is currently working as a chair of the Mechanical Engineering Department at Al-Hussein Bin Talal University, Jordan. He received his Ph.D. from the University of Technology Sydney, Australia, in 2019. His research interests include designing and developing oscillating water column devices used to harvest ocean wave energy.

Ahmed Elhanafi, born in 1985, is currently working at the National Centre for Maritime Engineering and Hydrodynamics (NCMEH), Australian Maritime College. He received his Ph.D. on wave energy converters, structural engineering, ocean engineering and naval engineering in University of Tasmania, Australia, in 2018.

Paul Walker is currently working as Senior Lecturer at School of Mechanical and Mechatronic Engineering in the University of Technology, Sydney. His research interests cover dynamics and control of vehicle powertrains and the development of novel hybrid and electric vehicle powertrain architectures, including design, integration, and transient dynamic analysis.

David G. Dorrell, has a BEng (Hons) from The University of Leeds (1988), MSC from The University of Bradford (1989) and PhD from The University of Cambridge (1993). He is currently a Distinguished Professor with The University of the Witwatersrand. He was Professor of Electrical Machines with The University of KwaZulu-Natal in Durban, South Africa (2015-2020) and Director of the EPPE Specialization Centre in HVDC and FACTS at UKZN (2016-2020). He has held positions with The Robert Gordon University, UK, The University of Reading, UK, The University of Glasgow, UK, and the University of Technology Sydney, Australia. His research interests cover electrical machines, renewable energy and power systems. He has worked in industry and carried out several industrial consultancies. He is a Chartered Engineer in the UK and a Fellow of the IET.

Ahmad Salah, born in 1985, is currently working as a chair of the Electrical Engineering Department at Al-Hussein Bin Talal University, Jordan. He received his Ph.D. from the University of Technology Sydney, Australia, in 2018. His research interests cover electrical machines, renewable energy and power systems.

Mohamed Behiri, born in 1979, is currently working as Assis. Prof. of thermal and renewable energy, mechanical engineering at Benha Faculty of Engineering, Benha University, Banha, Egypt and at Mechanical Engineering Department at Al-Hussein Bin Talal University, Jordan. He received his Ph.D. from the SEUA (Polytechnic), Yerevan, Armenia, on December 2011 in the field of renewable energy systems. His research interests include thermal and renewable energy systems, absorption, desalination and air-conditioning systems.

\section{Authors' Contributions}

MS, AE, DGD and PW provide the conception and design of the study, and were in charge of the acquisition of data. MS, AE, DGD, AS were in charge of analysis and interpretation of data. Drafting the manuscript: MS, AE, DG D, AS, MRG drafted and revised the manuscript critically for important intellectual content. All authors read and approved the final manuscript.

\section{Funding}

Not applicable.

\section{Competing Interests}

The authors declare no competing financial interests.

\section{Author Details}

${ }^{1}$ Mechanical Engineering Department, Faculty of Engineering, Al-Hussein Bin Talal University, Ma'an 71111, Jordan. ${ }^{2}$ National Centre for Maritime Engineering and Hydrodynamics, Australian Maritime College, University of Tasmania, Launceston, TAS 7250, Australia. ${ }^{3}$ School of Mechanical and Mechatronic Systems, University of Technology Sydney, Sydney, NSW 2007, Australia. ${ }^{4}$ School of Electrical and Information Engineering, University of the Witwatersrand, Durban 2000, South Africa. ${ }^{5}$ Electrical Engineering Department, Faculty of Engineering, Al Hussein Bin Talal University, Ma'an 71111, Jordan. ${ }^{6}$ Mechanical Engineering Department, Benha Faculty of Engineering, Benha University, Benha 13518, Egypt.

\section{Received: 21 December 2020 Revised: 5 September 2021 Accepted: 3}

November 2021

Published online: 04 December 2021

\section{References}

[1] A M Levenda, I Behrsin, F Disano, et al. Renewable energy for whom? A global systematic review of the environmental justice implications of renewable energy technologies. Energy Research \& Social Science, 2021, 71: 101837.

[2] I Fairley, M Lewis, B Robertson, et al. A classification system for global wave energy resources based on multivariate clustering. Applied Energy, 2020, 262: 114515.

[3] L Chen, W Li, J Li, et al. Evolution trend research of global ocean power generation based on a 45-year scientometric analysis. J. Mar. Sci. Eng., 2021. 9(2): 218.

[4] N Guillou, G Lavidas, G Chapalain. Wave energy resource assessment for exploitation-A review. J. Mar. Sci. Eng., 2020, 8(9): 705.

[5] HX Li, D J Edwards, M R Hosseini, et al. A review on renewable energy transition in Australia: An updated depiction. Journal of Cleaner Production, 2020, 242: 118475.

[6] M A Hemer, R Manasseh, K L Mclnnes, et al. Perspectives on a way forward for ocean renewable energy in Australia. Renewable Energy, 2018, 127: 733-745.

[7] N Pearre, L Swan. Combining wind, solar, and in-stream tidal electricity generation with energy storage using a load-perturbation control strategy. Energy, 2020, 203: 117898.

[8] A Heidari, A E Nezhad, A Tavakoli, et al. A comprehensive review of renewable energy resources for electricity generation in Australia. Frontiers in Energy, 2020, 14(3): 510-529.

[9] T Calheiros-Cabral, D Clemente, P Rosa-Santos, et al. Evaluation of the annual electricity production of a hybrid breakwater-integrated wave energy converter. Energy, 2020. 213: 118845.

[10] J C C Portillo, K M Collins, R P F Gomes, et al. Wave energy converter physical model design and testing: The case of floating oscillating-watercolumns. Applied Energy, 2020, 278: 115638.

[11] M S Chowdhury, K S Rahman, V Selvanathan, et al. Current trends and prospects of tidal energy technology. Environment, Development and Sustainability, 2021, 23(6): 8179-8194.

[12] Y Zhang, Y Zhao, W Sun, et al. Ocean wave energy converters: Technical principle, device realization, and performance evaluation. Renewable and Sustainable Energy Reviews, 2021, 141: 110764.

[13] António F de O Falcão. Wave energy utilization: A review of the technologies. Renewable and Sustainable Energy Reviews, 2010, 14(3): 899-918.

[14] R Ahamed, K McKee, I Howard. Advancements of wave energy converters based on power take off (PTO) systems: A review. Ocean Engineering, 2020, 204: 107248.

[15] Dezhi Ning, Yu Zhou, Robert Mayon, et al. Experimental investigation on the hydrodynamic performance of a cylindrical dual-chamber oscillating water column device. Applied Energy, 2020, 260: 114252.

[16] M Shalby, D G Dorrell, P Walker. Multi-chamber oscillating water column wave energy converters and air turbines: A review. International Journal of Energy Research, 2019, 43(2): 681-696.

[17] Gabriel Ibarra-Berastegi, Jon Sáenz, Alain Ulazia, et al. Electricity production, capacity factor, and plant efficiency index at the Mutriku wave farm (2014-2016). Ocean Engineering, 2018, 147: 20-29.

[18] António F O Falcão, João C C Henriques. Oscillating-water-column wave energy converters and air turbines: A review. Renewable Energy, 2016, 85: 1391-1424.

[19] M Nachtane, M Tarfaoui, I Goda, et al. A review on the technologies, design considerations and numerical models of tidal current turbines. Renewable Energy, 2020, 157: 1274-1288.

[20] M Shalby, DG Dorrell, P Walker, et al. An experimental investigation into the wave power extraction of a small-scale fixed multi-chamber OWC device. IEEE Energy Conversion Congress and Exposition (ECCE), IEEE, 2019: 4982-4987.

[21] Dezhi Ning, Rong-Quan Wang, Qing-Ping Zou, et al. An experimental investigation of hydrodynamics of a fixed OWC Wave Energy Converter. Applied Energy, 2016, 168: 636-648.

[22] H Coleman W, WG Steele. Experimentation, validation, and uncertainty analysis for engineers. John Wiley \& Sons, 2018. 
[23] B Holmes. Tank testing of wave energy conversion systems: marine renewable energy guides. European Marine Energy Centre, 2009.

[24] G S Payne, J Taylor, David Ingram. Best practice guidelines for tank testing of wave energy converters. 2009, 4(4): 38-70.

[25] M G Hughes, A D J R E Heap. National-scale wave energy resource assessment for Australia. Renewable Energy, 2010, 35(8): 1783-1791.

[26] Department of the Environment and Energy of Australia. Australian energy update, 2017-09-01.

[27] Bin Lu, Andrew Blakers, Matthew Stocks, et al. A zero-carbon, reliable and affordable energy future in Australia. Energy, 2021, 220: 119678.

[28] Behrens Sam; Griffin David; Hayward Jenny, et al. Ocean renewable energy: 2015-2050: An analysis of ocean energy in Australia. 2012. https://doi.org/10. 4225/08/584af1865b172.

[29] D G Dorrell, S. Kazi, and M. Papadopoulos. Wave generator modelling using an oscillating water column and a wells turbine. in third IASTED international conference on power and energy systems. 2003.

[30] D G Dorrell, J R Halliday, P Miller, et al. Review of wave energy resource and oscillating water column modelling. in 39th International Universities Power Engineering Conference, IEEE, Bristol, UK, 2004.

[31] D G Dorrell, JR Halliday, S MacLean, et al. Development of small-scale facilities for initiating studies into Sea wave energy generation. in International Conference on Renewable Energy and power Quality. 2005: https://doi.org/ 10.24084/repqj03.314

[32] MF Hsieh, I.-Hsien Lin, David G. Dorrell, et al. Development of a wave energy converter using a two chamber oscillating water column. IEEE Transactions on Sustainable Energy, 2012, 3(3): 482-497.

[33] M Shalby, P. Walker, D G. Dorrell. The investigation of a segment multi-chamber oscillating water column in physical scale model. in 2016 IEEE International Conference on Renewable Energy Research and Applications (ICRERA). IEEE. 2016.

[34] Y Goda. Random seas and design of maritime structures. World Scientific Publishing Company, 2010.

[35] F He, Z J O E Huang. Hydrodynamic performance of pile-supported OWC-type structures as breakwaters: an experimental study. Ocean Engineering, 2014. 88: 618-626.

[36] TVyzikas, S Deshoulières, M Barton, et al. Experimental investigation of different geometries of fixed oscillating water column devices. Renewable Energy, 2017, 104: 248-258.

[37] K Rezanejad, C Guedes Soares, I López, et al., Experimental and numerical investigation of the hydrodynamic performance of an oscillating water column wave energy converter. Renewable Energy, 2017, 106: 1-16.

[38] M Fossa, G J ET Guglielmini, F Science. Pressure drop and void fraction profiles during horizontal flow through thin and thick orifices. Experimental Thermal and Fluid Science, 2002, 26(5): 513-523.

[39] D Chisholm. Two-phase flow in pipelines and heat exchangers. US: G. Godwin in association with Institution of Chemical Engineers, 1983.

[40] Standard, I.J.I., Geneva, Switzerland, Measurement of fluid flow by means of pressure differential devices. 5167-1.1991.

[41] RM Sorensen, Basic coastal engineering. Springer Science \& Business Media, 2005.

[42] $\mathrm{F} \mathrm{He}$, J Leng, $X$ Zhao. An experimental investigation into the wave power extraction of a floating box-type breakwater with dual pneumatic chambers. Applied Ocean Research, 2017, 67: 21-30.

[43] A Elhanafi, G Macfarlane, D Ning, Hydrodynamic performance of singlechamber and dual-chamber offshore-stationary Oscillating Water Column devices using CFD. Applied Energy, 2018, 228: 82-96.

[44] A Elhanafi, A Fleming, G Macfarlane, et al. Numerical energy balance analysis for an onshore oscillating water column-wave energy converter. Energy, 2016, 116: 539-557.

[45] R A Gonçalves, Paulo R F Teixeira, Eric Didier, et al. Numerical analysis of the influence of air compressibility effects on an oscillating water column wave energy converter chamber. Renewable Energy, 2020. 153: 1183-1193.
[46] David G Dorrell, Min-Fu Hsieh, Chi-Chien Lin. A small segmented oscillating water column using a Savonius rotor turbine. IEEE Transactions on Industry Applications, 2010. 46(5): 2080-2088.

[47] A Elhanafi, C Kim. Experimental and numerical investigation on wave height and power take-off damping effects on the hydrodynamic performance of an offshore-stationary OWC wave energy converter. Renewable Energy, 2018. 125: 518-528.

[48] F He, M Li, Z Huang. An experimental study of pile-supported OWC-type breakwaters: energy extraction and vortex-induced energy loss. Energies, 2016, 9(7): 540

[49] L Martinelli, P Ruol, E Fassina, et al. A wave-2-wire experimental investigation of the new" seabreath + wave energy converter: the hydraulic response. Coastal Engineering Proceedings, 2014(34): 29.

[50] A Elhanafi, A Fleming, G Macfarlane, et al. Numerical hydrodynamic analysis of an offshore stationary-floating oscillating water column-wave energy converter using CFD. International Journal of Naval Architecture and Ocean Engineering, 2017, 9(1): 77-99.

[51] I López, B Pereiras, F Castro, et al. Optimisation of turbine-induced damping for an OWC wave energy converter using a RANS-VOF numerical model. Applied Energy, 2014, 127: 105-114.

[52] A Kamath, H Bihs, $\varnothing$ Arntsen. Numerical modeling of power take-off damping in an oscillating water column device. International Journal of Marine Energy, 2015, 10: 1-16.

[53] I Simonetti, L Cappietti, H Elsafti, et al. Optimization of the geometry and the turbine induced damping for fixed detached and asymmetric OWC devices: A numerical study. Energy, 2017. 139: 1197-1209.

[54] Michael T Morris-Thomas, Rohan J Irvin, Krish P Thiagarajan, An investigation into the hydrodynamic efficiency of an oscillating water column. J. Offshore Mech. Arct. Eng., 2007 129(4): 273-278.

[55] A Elhanafi, G Macfarlane, A Fleming, et al. Experimental and numerical investigations on the hydrodynamic performance of a floating-moored oscillating water column wave energy converter. Applied Energy, 2017, 205: 369-390.

[56] A Elhanafi, G Macfarlane, A Fleming, et al. Experim ental and numerical investigations on the intact and damage survivability of a floating-moored oscillating water column device. Applied Ocean Research, 2017, 68: 276-292.

[57] ISO, I. and B.J.G. OIML, Switzerland, Guide to the Expression of Uncertainty in Measurement. 1995. 122: 16-17.

[58] Procedures, I.R.J.R.T., 23rd ITTC, Guidelines 7.5-02.02.01,"Testing and Extrapolation Methods. 2002.

[59] ITTC, R.P.J.I.R.P. and P. Guidelines, Guidelines: Testing and Extrapolation Methods: Resistance-Uncertainty Analysis, Example for Resistance Test. 2002: 7.5-02

\section{Submit your manuscript to a SpringerOpen ${ }^{\oplus}$ journal and benefit from:}

- Convenient online submission

- Rigorous peer review

- Open access: articles freely available online

- High visibility within the field

Retaining the copyright to your article

Submit your next manuscript at $\boldsymbol{\nabla}$ springeropen.com 